\title{
Social Networking Sites and Internet Addiction among Adult Internet Users in Greece
}

\author{
Spyridon Kordonis, Klimis Ntalianis, Vasiliki Kikili, Filotheos Ntalianis
}

Received: July 15, 2020. Revised: November 8, 2020. Accepted: November 10, 2020. Published: November 11, 2020.

\begin{abstract}
For the majority of Internet users, the Network represents the endless source of opportunities that enhance wellbeing. For some though, it might be the reason that makes them "sick" with symptoms specific to mental disorder. This condition is called Internet addiction and is described as "impulse control disorder that does not involve addictive substance". In recent years Social Networking Sites (SNSs) have provided many and significant benefits to users. At the same time, though, there are risks with their use, such as excessive use that can lead to addiction phenomena as well as contribute to the manifestation of Internet addiction. The present study investigates the phenomenon of Internet addiction in adult Greek users of Social Networking Sites, to determine the prevalence of IA among SNS users, and investigates the correlation of socio-demographic factors with the occurrence of IA in SNS users. The results showed that there is connection between the use of SNS and IA, and the prevalence of IA among SNS users reaches 30\%. Moreover, IA relates to the age of SNS users.
\end{abstract}

Keywords - Internet Addiction, Social Networks, Social Media, Cyberspace Addiction, Compulsive Internet Use.

\section{INTRODUCTION}

$\mathrm{T}$ HE internet is perhaps the only human achievement of the modern age, which affects every aspect of human existence, to the extent which can only be compared to the corresponding impact of the Industrial Revolution, because like the Industrial Revolution, it changed the structure and the ways in which people communicate, trade, produce and operate in their daily lives.

One of the most catalytic effects of the rapid growth of the Internet and its invasion of almost all facets of human activity is the mediation of social relationships through information and communication technologies. Social reality is now characterized by the increasing participation of people in digital communities (blogs, wikis, social networks, social tagging, etc.) and the use of online social computing applications (recommendation, reputation, decision analysis, edutainment, gaming, training, etc.) (Wang et al., 2007, [1]).

This work was supported in part by Interbit Research (http://www.interbitresearch.com/).

S. Kordonis is with the Open University of Cyprus, 3, Giannou Kranidioti Ave., 2220, Latsia, Nicosia, CYPRUS (e-mail: spyridon.kordonis@st.ouc.ac.cy, kordoniss@gmail.com).

K. Ntalianis is with the Department of Business Administration, University of West Attica, Egaleo, Athens, Greece (e-mail: kntal@uniwa.gr).

V. Kikili is with the Ministry of Education and Religious Affairs, Directorate of Primary Education, Athens, Greece (e-mail: vasikik@gmail.com).

F. Ntalianis is with the Department of Business Administration, University of Piraeus, Piraeus, Greece (e-mail: filotheos@unipi.gr)
There are many reasons for using Social Networks. Among the most important are: homophily and influence (Kadushin, 2012, [2]), the construction of so-called Social Capital (Bourdieu, 2008, [3]), (Ellison et al., 2006, [4]), self-identity which is very important for people of post-modernity (frequent change of identity), the need of 'belonging' (Pelling \& White, 2009, [5]), as well as the expression of opinion, the sharing of favorite music or video, the flirtation, the exploration of interests, the possibility of meeting new people or friends, staying in touch with family, filling up free time or just because friends have an account (Jarvi et al., 2017, [6]).

Dealing with these social media platforms can have an impact on people's behavior and can be expressed in a positive or negative way.

One of the negative effects that can result from dealing with the functions and services offered on the Internet is the addiction to it. Internet addiction (IA) is a mental disorder that presents similar symptoms to other types of addictions (drugs, alcohol, gambling, etc.). Internet addiction is manifested through behavior characterized by loss of control over the media and is directly related to the use of Social Networks, online games, and other online activities. This behavior can lead to a significant deterioration in one's social and occupational or academic functionality through abandonment of many other vital activities (social, professional, etc.) of the addicted person (Chlapanis et al., 2015, [7]).

Although there is no specific term or definition for Internet abuse, various terms have been put forward by various scientists at times - with the corresponding each time evaluation criteria - such as: Internet addiction, Internet dependency, Internet abuse, compulsive Internet use, pathological Internet use and problematic Internet use, reflecting the various inceptions of the concept of Internet abuse (Monahan-Martin, 2008, [8]). The first and still popular definition for Internet addiction was presented by K.S. Young (1996) [9], which defined IAas "impulse-control disorder that does not involve addictive substance". However, the situation is perhaps best described by the term Compulsive Internet Use (CIU), because according to Meerkerk et. al. (2006) [10], the observed online behavior with addiction characteristics, cannot be defined as internet addiction since the user, is not actually addicted to the network itself but to the application (or service) he/she uses.

Research has shown that first, there is a relationship between Internet use or Social Networking Sites and users' psychological well-being, and even pre-existing psychological 
well-being and stable social characteristics both influence how people use the Internet and SNSs, as well as their social and psychological well-being as users. Second, there are different types of Internet use as well as use by different types of people, with the result that different uses may have distinct correlations with well-being for different types of people (Kraut \& Burke, 2015, [11]), and thus addictive behavior of users may differentiate accordingly with the Internet and SNSs.

The use of SNSs is not only a factor contributing to the emergence of Internet addiction but can also lead to autonomous form of addiction especially to SNSs. Addiction to SNS is defined as "overly concerned with SNS, driven by a strong motivation to connect or use SNS and devote so much time and effort to SNS that it can harm other social activities, studies/work, interpersonal relationships and/or psychological health and wellness" (Andreassen, 2015, [12]).

The purpose of the study is to determine the role and extent of Social Networking Sites' impact on the emergence or exacerbation of Internet addiction phenomena among adult Greek Internet users. The expected results of the research include, determining the degree of penetration of the Internet and Social Networking Sites in the adult population, determining the relationship between the use of Social Networking Sites with the development of addictive / compulsive Internet use phenomena, and the determination of the relationship between the demographic characteristics of the adult Social Networking Sites users with the manifestation of Internet Addiction/Compulsive Internet Usage Phenomena.

To fulfill the scope of the study, the following research questions were stated:

1. What is the degree of penetration of Social Networking Sites (participation in Social Networks) in the adult Greek Internet Users and which are the most popular platforms? What are the Prevalence Levels of Compulsive Internet Use among Users and Non-Users?

2. How does the use of Social Networking Sites (SNSs) relate to the occurrence of Internet Addiction/Compulsive Internet Usage among adult Greek Internet Users?

3. What is the relationship between the socio-demographic characteristics of adult Greek Social Network Users and the occurrence of Internet Addiction/Compulsive Internet Usage?

\section{RELATED WORK}

From the literature review on the topic of Internet Addiction/Compulsive Internet Use, it became clear that the vast majority of the various studies concerned the research and study of the occurrence of such phenomena in youth groups and mainly high school students and junior-high students, University students and young adults.

Various research studies have examined different aspects and dimensions of the topic of Internet Addiction/Compulsive Internet Use.

Approaching thematically the reviewed literature, we can say that the vast majority of the studies deal with the measurement and prevalence of Internet Addiction in its various conceptions (depending on the definition used). These include the studies (K.S. Young, 1996, [9]), (Song et al., 2004, [13]), (Mann Hyung Hur, 2006, [14]), (Demetrovics et al., 2008, [15]), (K. E. Siomos et al., 2008, [16]), (Tsitsika et al., 2009, [17]), (Frangos et al., 2010, [18]), (Frangos et al., 2011, [19]), (Kerkhof et al., 2011, [20]), (K. Siomos et al., 2012, [21]), (Fioravanti et al., 2012, [22]), (Andreou \& Svoli, 2013, [23]), (Marzano et al., 2013, [24]), (Hormes et al., 2014, [25]), (Cheng \& Li, 2014, [26]), (Simsek \& Sali, 2014, [27]), (Wegmann et al., 2015, [28]), (Pontes et al., 2015, [29]), (Chlapanis et al., 2015, [7]), (Iordache \& Manea, 2016, [30]), (Abd Rahman \& Stephen, 2016, [31]), (Domínguez-Vergara \& Ybañez-Carranza, 2016, [32]), (Pontes, 2017, [33]), (Savci \& Aysan, 2017, [34]) and (Lindenberg et al., 2018, [36]).

The subject of the impact of Internet addiction is dealt with by the studies (K.S. Young, 1996, [9]), (De Cock et al., 2014, [39]), (Iordache \& Manea, 2016, [30]), (Abd Rahman \& Stephen, 2016, [31]), (Domínguez-Vergara \& YbañezCarranza, 2016, [32]), (Pontes, 2017, [33]) and (Savci \& Aysan, 2017, [34]).

The subject of Measures (Questionnaires) of Internet Addiction or its various approaches (Compulsive Internet Use, Problematic Internet Use, etc.) is dealt with by the studies (K.S. Young, 1996, [9]), (Demetrovics et al., 2008, [15]), (K. E. Siomos et al., 2008, [16]), (Simsek \& Sali, 2014, [27]), (Carbonell \& Panova, 2017, [35]) and (Lindenberg et al., 2018, [36]).

Issues related to the factors (aggravating, predictive) of Internet Addiction, such as Diagnosis, Prevention and Prevention Models, are dealt with by the studies (Mann Hyung Hur, 2006, [14]), (Demetrovics et. al., 2008, [15]), (K. E. Siomos et al., 2008, [16]), (Tsitsika et al., 2009, [17]), (Frangos et al., 2010, [18]), (Frangos et al., 2011, [19]), (Kerkhof et al., 2011, [20]), (K. Siomos et al., 2012, [21]), (Fioravanti et al., 2012, [22]), (Andreou \& Svoli, 2013, [23]), (Marzano et al., 2013, [24]), (Simsek \& Sali, 2014, [27]), (Wegmann et al., 2015, [28]), (Chlapanis et al., 2015, [7]), (Iordache \& Manea, 2016, [30]) and (Lindenberg et al., 2018, [36]).

The topic of predisposition to Internet addiction and the risk profile is dealt with by the studies (Song et al., 2004, [13]), (Carbonell \& Panova, 2017, [35]) and (Hawi \& Samaha, 2019, [38]).

The issue of Social Networks in relation to Internet Addiction is dealt with by the studies (Julia Ying-Chao Lin et. al., 2012, [37]), (De Cock et al., 2014, [39]), (Hormes et al., 2014, [25]), (Wegmann et al., 2015, [28]), (Iordache \& Manea, 2016, [30]), (Abd Rahman \& Stephen, 2016, [31]), (Domínguez-Vergara \& Ybañez-Carranza, 2016, [32]), (Pontes, 2017, [33]), (Savci \& Aysan, 2017, [34]), (Kuss \& Griffiths, 2017, [40]) and (Hawi \& Samaha, 2019, [38]).

The issue of the types and conceptual approaches of Internet Addiction is dealt with by the studies (De Cock et al., 2014, [39]), (Hormes et al., 2014, [25]), (Wegmann et al., 2015, [28]), (Kuss \& Griffiths, 2017, [40]), (Lindenberg et al., 2018, [36]) and (Hawi \& Samaha, 2019, [38]).

Finally, the topic of Internet Activities and Quality of Life is dealt with by the study (Pontes et al., 2015, [29]). 
The study of the literature has shown that the overwhelming amount of research and studies relates to adolescents and especially to secondary education students and to students of Universities or other higher education institutions and young adults. Therefore, it seems that the study of the phenomenon in the general population is extremely limited. Especially in Greece, current literature has shown that there is very limited research on Internet Addiction in the general adult population. Especially in the area of the contribution of Social Networking Sites to the prevalence of Compulsive Internet Use/Internet Addiction, in the area of the general adult population, it was not possible to locate any research and studies related to the subject.

The dynamics of the development of Social Media platforms and their continuous dissemination to ever larger segments of the population, almost necessarily creates the need for continuous study of the phenomenon. Therefore, further research into identifying Compulsive Internet Use among Greek SNS users is a legitimate pursuit.

The present study partially addresses the need for information on the relationship between SNS usage and Compulsive Internet Use/Internet Addiction in the general population of Greece and contributes to the updating of information regarding the topic of Compulsive Internet Use among the adult Internet users in Greece.

\section{RESEARCH PREREQUISITES}

The study is quantitative based on a survey research model with questionnaire. The study intends to examine the relationship between Internet addiction or rather Compulsive Internet Use and the use of Social Networks in the adult population of Greek Internet users and the relationship between different demographic characteristics and Internet use.

A non-random population sample of over 4100 people were conducted through targeted (country and age) Facebook invitations to friends who were asked to participate in the survey and forward the questionnaire in their own friends' networks and by posting to special interests' groups on Facebook. Also, there was access, through the appropriate channels, to mailing lists of employees of a large public Agency, to recruit individuals interested in online survey to assess internet addiction phenomena and the role of social networking sites in it. The Facebook post included a brief description of the reasons for the invitation, confirmation of the anonymity of the data and a link to the survey questionnaire. An email invitation was also sent to over 3800 people of the Agency with a brief description of the reasons for the survey, assurance for anonymity and protection of personal data and a link to the questionnaire. At least twice, after about two weeks each time, the invitation was reposted on Facebook. There was also a reminder for the invitation to the survey to the Agency's employees Facebook account.

Access to the e-mails of civil servants (Agency employees) was requested and granted with the necessary authorization by the administration of the Agency.

The survey was conducted from 25 July 2019 to 20
September 2019, via the Internet. All participants who were invited to participate through the Agency's email services were eligible, as were those invited via Facebook. Eventually a total of 415 people participated in the survey and completed the questionnaire.

The data were collected through the questionnaire "Social Network and Internet Addiction Relationship Assessment Questionnaire". The tool included subscales for demographics (gender, age, educational level), online habits (ways and means of connecting to the Internet, frequency of connection, etc.), Social Networking Sites (account in SNSs, select specific SNSs, login frequency on specific SNSs, etc.), measuring SNS Usage in general, and measuring the degree of Compulsive Internet Use (Internet Addiction).

The 9-item "General Social Media Usage Subscale" of the "Media and Technology Usage and Behavior ScaleMTUAS)" (Rosen \& Whaling, n.d., [41]) was used to measure the degree of SNS Usage of SNS users (account), translated into Greek by the author. The reliability score of the original questionnaire is Cronbach's alpha $=0.97$. The translated subscale was measured for its reliability using SPSS and was found a score of Cronbach's alpha $=0.825$. The data for the degree of SNS usage were measured on a Likert scale from 1 (never) to 7 (many times a day). The greater the degree, the more frequent the use of SNSs.

The Weighted 8-Question Scale "Short form of the Compulsive Internet Use Scale (CIUS)" (Gmel et al., 2019, [42]), translated into Greek by the author, was used to measure Compulsive Internet Use (Internet addiction). The data examines the degree of Compulsive Internet Use (degree of "addiction" to Internet use) on a Likert scale from 0 (never) to 4 (very often). The score ranges from 0 to 32 with a cut-off score of 13 . The original questionnaire has a reliability score of Cronbach's alpha $=0.821$ (Gmel et al., 2019, [42]). The translated questionnaire used in the survey was tested for reliability and had a score of Cronbach's alpha $=0.874$.

The questionnaire was developed using Google's Forms app and distributed to participants via Facebook and email. The questionnaire provided confirmation of the anonymity of participants' data and information on the research and purpose.

IBM SPSS v.26.0 for Mac was used for data processing, statistical analysis, output of tables, images and graphics. The prevalence of Compulsive Internet Use was calculated according to the established cut-off score.

\section{EXPERIMENTAL RESULTS}

Of the 415 participants, 299 (72\%) were women and 116 $(28 \%)$ were men. The age composition of the sample consisted of $148(35.7 \%)$ persons in the age group of 18-40 years, 254 $(61.2 \%)$ persons in the age group of 41-64 years and 13 $(3.1 \%)$ persons in the category of $>65$ years. In terms of education level, 4 (1\%) persons had Compulsory Education up to Junior High, $40(9.6 \%)$ had Secondary Education, while 371 (89.4\%) had Higher Education.

The largest percentage (96.4\%) of Greek adult Internet users connects to the Internet from home, while Public Networks (Internet cafes / cafes / municipal networks / etc.) 
use only $40.5 \%$ of the users. Also important is the percentage $(72.8 \%)$ of users logging on from the Office or School. The majority $(88.4 \%)$ of Internet users are connected via smart phone or Tablet. Desktop and laptop use for connecting to the Internet is about the same ( $61 \%$ and $66 \%$ respectively).

In Figure 1 is shown the frequency of adult Greek Internet users logons:

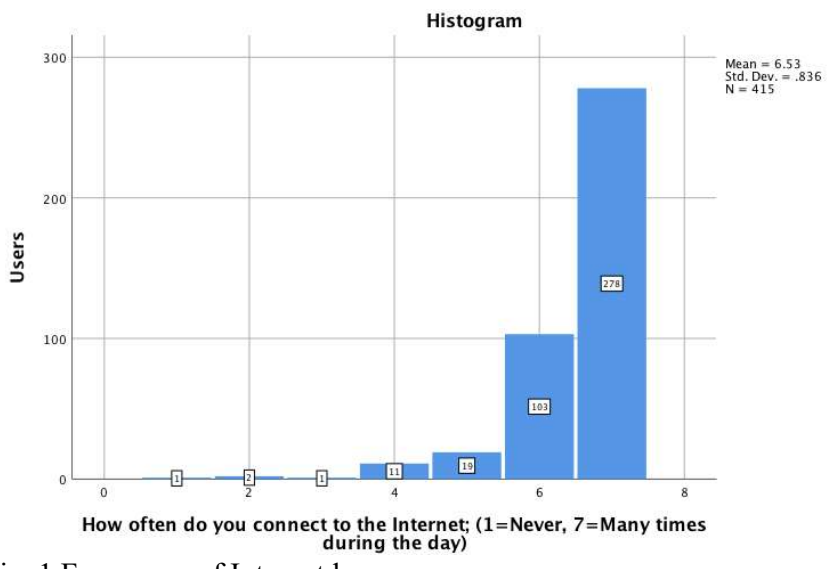

Fig. 1 Frequency of Internet logons

Regarding the results concerning the Research Question 1, we observe the following:

The vast majority (77.8\%) of Greek adult Internet users maintain one or more accounts on Social Networking Sites, while $22.2 \%$ does not have an SNS account.

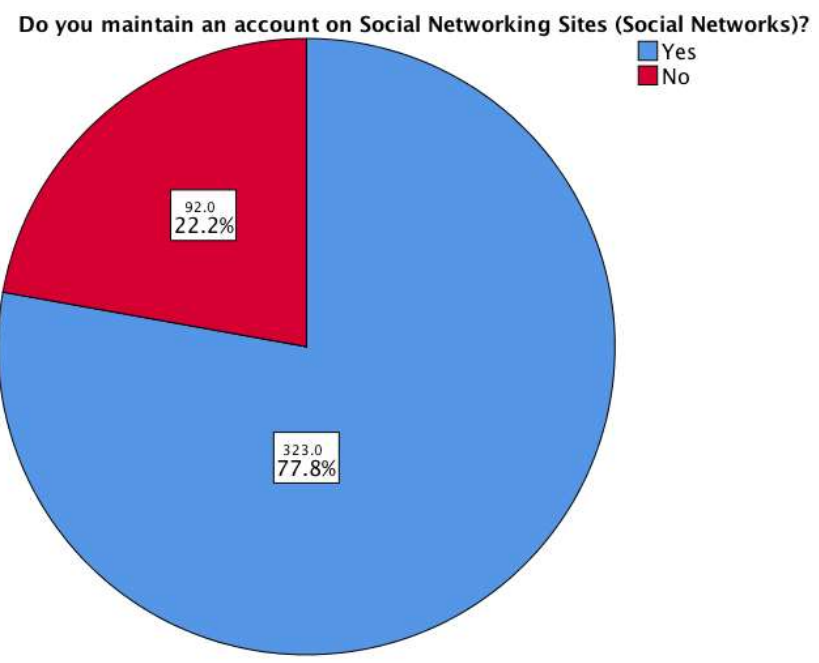

Fig. 2 Greek Adult Internet Users - SNS Users vs Non-SNS Users

The most popular platforms among SNS users of the Greek adult Internet users are Facebook with $94.7 \%$ penetration, followed by Instagram with $47.4 \%$, YouTube with $45.8 \%$ and Pinterest with $34.4 \%$.

As it can be seen from Figure 4 the majority (57.9\%) of the Greek adult SNS users, maintain from 2 to 4 accounts on Social Networking Sites.

Prevalence rate of Compulsive Internet Use among Greek adult SNS users is $30 \%$ and among non-SNS users is $12 \%$.

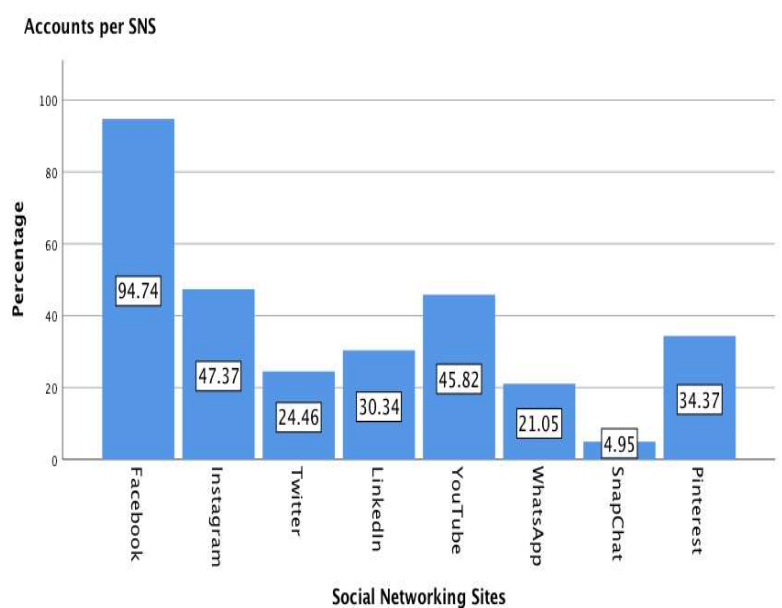

Fig. 3 Percentage of SNS users per Social Networking Site
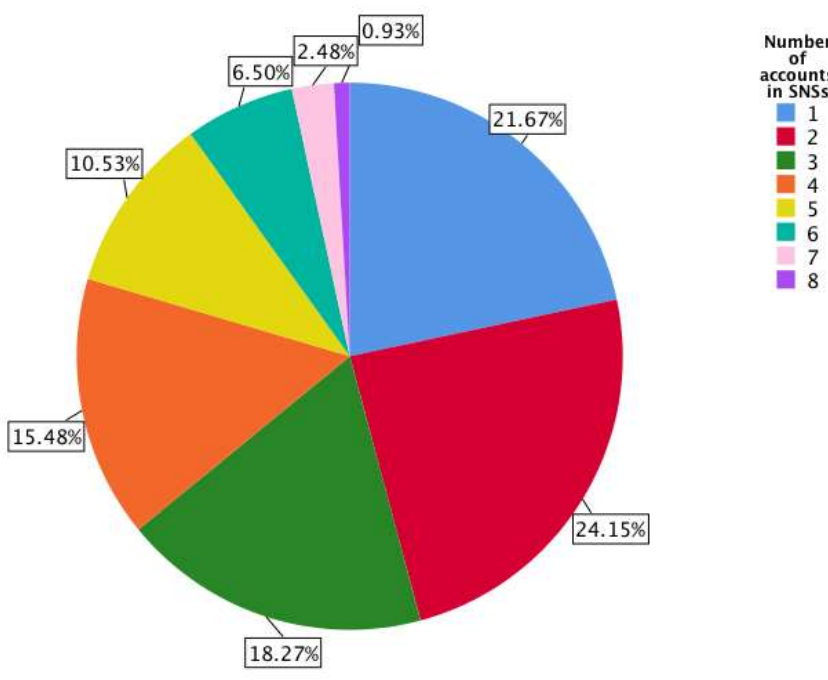

Fig. 4 Number of Accounts per SNS user

Regarding the results associated to the 2 nd and $3 \mathrm{rd}$ research questions, the situation is as follows:

To examine the relationship between Compulsive Internet Use and SNS usage, the following zero hypothesis was stated and tested H0: "There is no difference between SNS users (account) and non-SNS users regarding the Compulsive Internet Use" which was rejected, Mann-Whitney U ( $\mathrm{t}=$ $10295, \mathrm{n} 1=92, \mathrm{n} 2=323, \mathrm{p}<0.05)$. Therefore, the occurrence of Compulsive Internet Use (Internet Addiction) phenomena is directly related to the use of Social Networking Sites. This conclusion is reinforced by the result of the corresponding Spearman's Rho correlation test, which showed a statistically significant correlation ( $\mathrm{rs}=0.221, \mathrm{p}<0.01$ ) between Compulsive Internet Use and SNS participation.

Also, the results showed that, Compulsive Internet Use (CIU) is significantly related to the age of SNS users, and the difference in CIU is mainly observed between the age groups of 18-40 and 41-64. Regarding the relationship between the other socio-demographic characteristics and CIU, the results showed that there is no correlation between CIU manifestation and the gender or the education level of the SNS users. 


\begin{tabular}{ccccc}
\hline & & & & Valid \\
\hline Valid & 0 & 226 & 54.5 & 70.0 \\
& 1 & 97 & 23.4 & 30.0 \\
& Total & 323 & 77.8 & 100.0 \\
Missing & -1 & 92 & 22.2 & \\
Total & & 415 & 100.0 & \\
\hline
\end{tabular}

Table 1 Prevalence of Compulsive Internet Use among SNS users

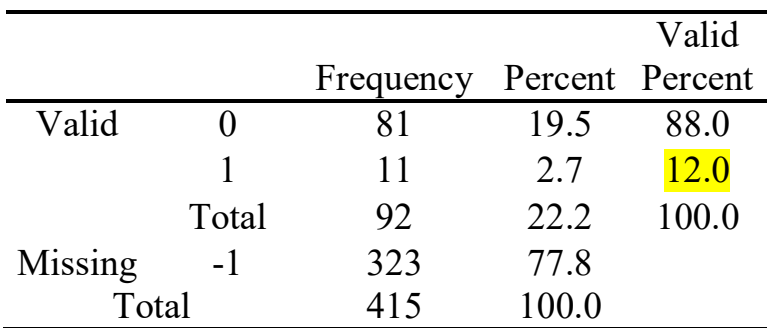

Table 2 Prevalence of Compulsive Internet Use among nonSNS users

Finally, the results showed that the degree of SNS usage is related to the age of users, while the education level or the gender of the users is not related to the degree of SNS usage.

\section{CONCLUSION \& FUTURE WORK}

The interest in Internet Addiction has increased significantly in recent years and this has led to increased research and studies on the subject, in order to better understand the status and the investigation of diagnostic, prognosis and treatment procedures. But there is still no agreement on its definition and therefore there is a problem in classifying it into the appropriate type of disorder which would allow for establishing specific methods and rules for diagnosis. Therefore, further studies and research on the subject should be encouraged.

The results of this research seem to agree with the findings of other studies presented in the literature review on the topic of Social Networks and Internet Addiction. The key finding of the research, that SNS use is related to Compulsive Internet Use (Internet Addiction), agrees with the findings of at least Simsek \& Sali's (2014) [27] study partly and those of Hawi \& Samaha (2019) [38] study.

One limitation of the study may relate to the sample population used, because the number of women in the sample is significantly larger than that of men. However, studies have shown that women are more involved in mediated technology and SNSs (Kimbrough et al., 2013, [43]) and more responsive to questionnaires filling out.

The present study may provide a starting point for further research on the topic of Internet Addiction or perhaps the most appropriate approach to the phenomenon as Compulsive Internet Use among the general population of Greece, with broader population samples and longitudinal studies.

\section{REFERENCES}

[1] Wang, F., Zeng, D., Carley, K. M., \& Mao, W. (2007). Social Computing: From Social Informatics to Social Intelligence. IEEE Intelligetnt Systems, march/april 2007, 79-83.

[2] Kadushin, C. (2012). Basic Network Concepts. In Understanding Social Networks. Oxford University Press.

[3] Bourdieu, P. (2008). The Forms of Capital. In Readings in Economic Sociology (pp. 280-291). John Wiley \& Sons, Ltd. https://doi.org/10.1002/9780470755679.ch15

[4] Ellison, N., Steinfield, C., \& Lampe, C. (2006). Spatially Bounded Online Social Networks and Social Capital: The Role of Facebook. 38.

[5] Pelling, E. L., \& White, K. M. (2009). The Theory of Planned Behavior Applied to Young People's Use of Social Networking Web Sites.

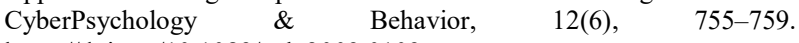
https://doi.org/10.1089/cpb.2009.0109

[6] Jarvi, S. M., Swenson, L. P., \& Batejan, K. L. (2017). Motivation for and use of social networking sites: Comparisons among college students with and without histories of non-suicidal self-injury. Journal of American College Health, 65(5), 306-312.

[7] Chlapanis, G., Minaidi, A., \& Loumani, M. (2015). Addiction to the Internet: Research in Five European Schools. Proceedings of the 8th Conference on the Use of Information and Communication Technologies in Teaching Practice. 8th Conference on the Use of Information and Communication Technologies in Teaching Practice, SYROS, GREECE. https://drive.google.com/file/d/0B6i1EVWz6r7mQzFaWkJoWUNkNV $\mathrm{U} /$ view

[8] Monahan-Martin, J. (2008). Internet Abuse: Emerging Trends and Lingering Questions. In Psychological Aspects of Cyberspace: Theory, Research, Applications. Cambridge University Press. http://search.ebscohost.com/login.aspx?direct=true \&db=e000xww\&AN $=263460 \&$ site $=$ eds-live

[9] Young, K.S. (1996). Internet addiction: The emergence of a new clinical disorder. CyberPsychology and Behavior, 1, 237-244. http://citeseerx.ist.psu.edu/viewdoc/download?doi=10.1.1.504.2805\&rep $=$ rep $1 \&$ type $=$ pdf

[10] Meerkerk, G.-J., Van Den Eijnden, R. J. J. M., \& Garretsen, H. F. L. (2006). Predicting compulsive Internet use: It's all about sex! Cyberpsychology \& Behavior: The Impact Of The Internet, Multimedia And Virtual Reality On Behavior And Society, 9(1), 95-103.

[11] Kraut, R., \& Burke, M. (2015). Internet use and psychological wellbeing: Effects of activity and audience. Communications of the ACM, 58(12), 94-100. https://doi.org/10.1145/2739043

[12] Andreassen, C. S. (2015). Online Social Network Site Addiction: A Comprehensive Review. Current Addiction Reports, 2(2), 175-184. https://doi.org/10.1007/s40429-015-0056-9

[13] Song, I., Larose, R., Eastin, M. S., \& Lin, C. A. (2004). Internet Gratifications and Internet Addiction: On the Uses and Abuses of New Media. CyberPsychology \& Behavior, 7(4), 384-394. https://doi.org/10.1089/cpb.2004.7.384

[14] Mann Hyung Hur. (2006). Demographic, Habitual, and Socioeconomic Determinants of Internet Addiction Disorder: An Empirical Study of Korean Teenagers. CyberPsychology \& Behavior, 9(5), 514-525. https://doi.org/10.1089/cpb.2006.9.514

[15] Demetrovics, Z., Szeredi, B., \& Rózsa, S. (2008). The three-factor model of Internet addiction: The development of the Problematic Internet Use Questionnaire. Behavior Research Methods, 40(2), 563574. https://doi.org/10.3758/BRM.40.2.563

[16] Siomos, K. E., Dafouli, E. D., Braimiotis, D. A., Mouzas, O. D., \& Angelopoulos, N. V. (2008). Internet Addiction among Greek Adolescent Students. CyberPsychology \& Behavior, 11(6), 653-657. https://doi.org/10.1089/cpb.2008.0088

[17] Tsitsika, A., Critselis, E., Kormas, G., Filippopoulou, A., Tounissidou, D., Freskou, A., Spiliopoulou, T., Louizou, A., Konstantoulaki, E., \& Kafetzis, D. (2009). Internet use and misuse: A multivariate regression analysis of the predictive factors of internet use among Greek adolescents. European Journal Of Pediatrics, 168(6), 655-665. https://doi.org/10.1007/s00431-008-0811-1

[18] Frangos, C. C., Fragkos, K. C., \& Kiohos, A. (2010). Internet Addiction among Greek University Students: Demographic Associations with the Phenomenon, Using the Greek Version of Young's Internet Addiction Test (SSRN Scholarly Paper ID 1664999). Social Science Research Network. https://papers.ssrn.com/abstract=1664999 
[19] Frangos, C. C., Frangos, C. C., \& Sotiropoulos, I. (2011). Problematic Internet Use among Greek university students: An ordinal logistic regression with risk factors of negative psychological beliefs, pornographic sites, and online games. Cyberpsychology, Behavior And $\begin{array}{lll}\text { Social Networking, } & 14(1-2), & 51-58\end{array}$ https://doi.org/10.1089/cyber.2009.0306

[20] Kerkhof, P., Finkenauer, C., \& Muusses, L. D. (2011). Relational Consequences of Compulsive Internet Use: A Longitudinal Study Among Newlyweds. Human Communication Research, 37(2), 147-173. https://doi.org/10.1111/j.1468-2958.2010.01397.x

[21] Siomos, K., Floros, G., Fisoun, V., Evaggelia, D., Farkonas, N., Sergentani, E., Lamprou, M., \& Geroukalis, D. (2012). Evolution of Internet addiction in Greek adolescent students over a two-year period: The impact of parental bonding. European Child \& Adolescent Psychiatry, 21(4), 211-219. https://doi.org/10.1007/s00787-012-0254-0

[22] Fioravanti, G., Dèttore, D., \& Casale, S. (2012). Adolescent Internet addiction: Testing the association between self-esteem, the perception of Internet attributes, and preference for online social interactions. Cyberpsychology, Behavior And Social Networking, 15(6), 318-323. https://doi.org/10.1089/cyber.2011.0358

[23] Andreou, E., \& Svoli, H. (2013). The Association between Internet User Characteristics and Dimensions of Internet Addiction among Greek Adolescents. International Journal of Mental Health and Addiction, $11(2), 139-148$

[24] Marzano, G., Lubkina, V., \& Truskovska, Z. (2013). Cyberspace's threats: A pedagogical perspective on Internet addiction, violence and abuse. http://www.siped.it/wp-content/uploads/2013/12/Pagine-dapedagogia oggi 2-2013-26092013-13.pdf

[25] Hormes, J. M., Kearns, B., \& Timko, C. A. (2014). Craving Facebook? Behavioral addiction to online social networking and its association with emotion regulation deficits. Addiction, 109(12), 2079-2088. https://doi.org/10.1111/add.12713

[26] Cheng, C., \& Li, A. Y. (2014). Internet Addiction Prevalence and Quality of (Real) Life: A Meta-Analysis of 31 Nations Across Seven World Regions. CyberPsychology, Behavior \& Social Networking, 17(12), 755-760. https://doi.org/10.1089/cyber.2014.0317

[27] Simsek, E., \& Sali, J. B. (2014). The Role of Internet Addiction and Social Media Membership on University Students' Psychological Capital. Contemporary Educational Technology, 5(3), 239-256.

[28] Wegmann, E., Stodt, B., \& Brand, M. (2015). Addictive use of social networking sites can be explained by the interaction of internet use expectancies, internet literacy, and psychopathological symptoms. Journal of Behavioral Addictions, 4(3), 155-162. https://doi.org/10.1556/2006.4.2015.021

[29] Pontes, H. M., Szabo, A., \& Griffiths, M. D. (2015). The impact of Internet-based specific activities on the perceptions of Internet addiction, quality of life, and excessive usage: A cross-sectional study. Addictive Behaviors Reports, 1, 19-25. https://doi.org/10.1016/j.abrep.2015.03.002

[30] Iordache, D. D., \& Manea, V. (2016). Gender differences in Facebook addiction. Romanian Journal of Human - Computer Interaction, 9(4), $339-351$

[31] Abd Rahman, S. H., \& Stephen, J. (2016). OMG (Oh My Grade)! Social Networking Sites Ruin My Academic Grades? Pertanika Journal of Social Sciences \& Humanities, 24(1), 483-494.

[32] Domínguez-Vergara, J. A., \& Ybañez-Carranza, J. (2016). Addiction to Social Networks and Social Skills in Students from a Private Educational Institution. Adicción a Las Redes Sociales y Habilidades Sociales En Estudiantes de Una Institución Educativa Privada., 4(2), 207-230. https://doi.org/10.20511/pyr2016.v4n2.122

[33] Pontes, H. M. (2017). Investigating the differential effects of social networking site addiction and Internet gaming disorder on psychological health. Journal of Behavioral Addictions, 6(4), 601-610. https://doi.org/10.1556/2006.6.2017.075

[34] Savci, M., \& Aysan, F. (2017). Technological Addictions and Social Connectedness: Predictor Effect of Internet Addiction, Social Media Addiction, Digital Game Addiction and Smartphone Addiction on Social Connectedness. Teknolojik Bağımlılıklar ve Sosyal Bağlılık: İnternet Bağımlılığı, Sosyal Medya Bağımlılı̆̆ı, Dijital Oyun Bağımlılığı ve Akıllı Telefon Bağımlılı̆̆ının Sosyal Bağlılığı Yordayıcı Etkisi., 30(3), 202-216. https://doi.org/10.5350/DAJPN2017300304

[35] Carbonell, X., \& Panova, T. (2017). A critical consideration of social networking sites' addiction potential. Addiction Research \& Theory, $25(1), 48$
[36] Lindenberg, K., Halasy, K., Szász-Janocha, C., \& Wartberg, L. (2018). A Phenotype Classification of Internet Use Disorder in a Large-Scale High-School Study. International Journal Of Environmental Research And Public Health, 15(4). https://doi.org/10.3390/ijerph15040733

[37] Julia Ying-Chao Lin, Angelina Nhat Hanh Le, Khalil, S., \& Julian Ming-Sun Cheng. (2012). Social Media Usage and Work Values: The Example of Facebook in Taiwan. Social Behavior \& Personality: An International Journal, 40(2), 195-200.

[38] Hawi, N., \& Samaha, M. (2019). Identifying commonalities and differences in personality characteristics of Internet and social media addiction profiles: Traits, self-esteem, and self-construal. Behaviour \& Information Technology, 38(2), 110-119. https://doi.org/10.1080/0144929X.2018.1515984

[39] De Cock, R., Vangeel, J., Klein, A., Minotte, P., Rosas, O., \& Meerkerk, G.-J. (2014). Compulsive use of social networking sites in Belgium: Prevalence, profile, and the role of attitude toward work and school. Cyberpsychology, Behavior And Social Networking, 17(3), 166-171. https://doi.org/10.1089/cyber.2013.0029

[40] Kuss, D. J., \& Griffiths, M. D. (2017). Social Networking Sites and Addiction: Ten Lessons Learned. International Journal of Environmental Research and Public Health, Vol 14, Iss 3, p 311 (2017), 3, 311. https://doi.org/10.3390/ijerph14030311

[41] Rosen, L., \& Whaling, K. (n.d.). The media and technology usage and attitudes scale: An empirical investigation. Retrieved June 5, 2019, from https://www.academia.edu/11818558/The media_and technology_usag $\mathrm{e}$ and attitudes scale An empirical investigation

[42] Gmel, G., Khazaal, Y., Studer, J., Baggio, S., \& Marmet, S. (2019). Development of a short form of the compulsive internet use scale in Switzerland. International Journal of Methods in Psychiatric Research, 28(1), e1765. https://doi.org/10.1002/mpr.1765

[43] Kimbrough, A. M., Guadagno, R. E., Muscanell, N. L., \& Dill, J. (2013). Gender differences in mediated communication: Women connect more than do men | Elsevier Enhanced Reader. Computers in Human Behavior, 29, 896-900. https://doi.org/10.1016/j.chb.2012.12.005

Spyridon Kordonis has completed (2019) the Master's program Social Information Systems of the Open University of Cyprus. His main research interests are in the areas of Internet Addiction, Cyberspace Addiction and Compulsive Internet Use.

Prof. Klimis Ntalianis received his diploma and Phd degrees both from the Electrical and Computer Engineering Department of the National Technical University of Athens (NTUA) in 1998 and 2003 respectively. From February 2020 he is a Professor at the West Attica University (Department of Marketing, Specialization: "Multimedia over the Internet"). Dr. Ntalianis has participated as editor in the proceedings of 3 International Conferences, he has written more than 150 scientific papers \& deliverables and has received more than 1,000 citations. His main research interests include multimedia processing, social media analysis, crowdsourcing and data mining.

Vasiliki Kikili received her Bachelor and Master's degrees both from the Department of Music Studies of the National and Kapodistrian University of Athens in 2009 and 2014 respectively. Her main research interests include music analysis over Social Networks, pedagogical aspects of social networking and online education.

Prof. Filotheos Ntalianis is an Assistant Professor at the Department of Business Administration, University of Piraeus. He has completed his Ph.D. at Concordia University, Montreal, Canada and Graduate studies at Florida Atlantic University, Boca Raton, Florida, USA. He is an active researcher and his work has appeared in academic journals and conferences. His research interests focus on the areas of motivation, personality, psychological contracts, employee physical activity and health.

\section{Creative Commons Attribution License 4.0 (Attribution 4.0 International, CC BY 4.0)}

This article is published under the terms of the Creative Commons Attribution License 4.0 https://creativecommons.org/licenses/by/4.0/deed.en US 